\title{
Research Article \\ Performance Evaluation of a B2C Model Based on Trust Requirements and Factors
}

\author{
Ahmad Yahya Asiri (iD and Sultan S. Alshamrani \\ Department of Information Technology, College of Computer and Information Technology, Taif University, P.O. Box 11099, \\ Taif 21944, Saudi Arabia \\ Correspondence should be addressed to Sultan S. Alshamrani; susamash@tu.edu.sa
}

Received 4 April 2021; Accepted 18 May 2021; Published 26 May 2021

Academic Editor: Sikandar Ali

Copyright (c) 2021 Ahmad Yahya Asiri and Sultan S. Alshamrani. This is an open access article distributed under the Creative Commons Attribution License, which permits unrestricted use, distribution, and reproduction in any medium, provided the original work is properly cited.

\begin{abstract}
This paper evaluates the performance of a newly proposed B2C e-commerce model based on trust factors and requirements in the context of Saudi Arabia. Two categories of trust factors, namely, governmental and nongovernmental types, are identified to create the model for determining the feasibility of an efficient online business strategy in the Kingdom. Data are collected over a duration of 10 weeks based on the designed questionnaire, carefully analyzed, and interpreted. The standpoint of the end user is analyzed to determine the influence of the proposed trust requirements and factors on B2C e-commerce in Saudi Arabia. The reliability of the questionnaires for each requirement with their factors is quantitatively analyzed using Cronbach's alpha. The questionnaire consists of three parts, namely, demographic component, questions related to the identified requirements, and additional notes as an open question. Questions are designed as per the requirements and the factors of trust models to demonstrate their possible relationship. Furthermore, the questionnaires' content validity is judged by expert lecturers with relevant specialization before distributing them, which are well organized together with easy understandability. They are randomly distributed among 222 academic and administrative staff (female and male) in addition to university students from the Faculty of Computer Science and Information System in Saudi Arabia. This random selection performed on total 222 responders ensures the statistical accuracy of the sampling. Adaptable government approaches, enactment, rules, insurance of buyer rights, and banking network situation with less web expenses are demonstrated to be significant to e-commerce expansion in the Kingdom. Implementation of the proposed model is believed to augment consumer self-confidence and reliance together with e-commerce growth in Saudi Arabia.
\end{abstract}

\section{Introduction}

Nowadays, the Internet is a necessary piece of present innovation and public activities. It made the world exceptionally small; thus, the idea of worldwide town is conjured. Beginning from air ticketing to hotel booking, every aspect has become simplistic for traveling overseas. Researchers often obtain their study materials and valuable information over the Internet. One can purchase books, articles, magazines, and literally any commodity online through various websites such as Amazon, Springer, IOT, ScienceDirect.com, and eBay. The reasonability of moving funds, covering bills, and updating individual data through the Internet banking administrations became attainable. These activities over the Internet made our life easy. Notwithstanding, every single step of collaboration with cyberspace via the Internet requires utter secrecy in addition to ultimate security, particularly during personal information exchange. Lately, the exponential escalation in Internet phishing and cyber forgery made the authenticity of a website doubtful. In this regard, trust in e-commerce plays a paramount role in terms of successful diverse implementation $[1,2]$.

The 21st century of information technology period is portrayed by the rapid trade and sharing of abundance of data. The improvement of rapid secured web access is an outright need in electronic trade. Thus, this provides associations and people the capacity to draw in into work regardless of time and spot. The web openness upgrades the movement as well as diminishes the expense and labor. This imaginative foundation carries benefits to business through 
upper hand and fulfills the differentiated interest of clients with their ideal determination. Online business is not simply restricted to purchasing, selling, and directing monetary exchanges through the Internet yet additionally incorporates trading and promoting various goods and services side by side $[3,4]$. Indeed, in the worldwide economy, web-intervened web-based business assumes a significant job.

Plainly, electronic trade is not simply restricted to online deals yet additionally covers numerous business exercises including on-the-web buying, studying, video conferencing, arrangement of assessments, interview with clients, online bill installment, exchange and settlement, conveyance following, and after-deal administration. In addition, every one of these exercises over the web requires proficiency, protection, and unwavering quality, and the main challenge is to improve them up to the degree of clients or clients' fulfillment. In this view, an innovative B2C e-commerce trust model is developed in the context of Saudi Arabia, and its performance is evaluated via a questionnaire survey to quantify the influence of trust factors and requirements on the user-friendly e-commerce environment with absolute secrecy and security for the online shopper.

The contributions of our work are as follows:

(1) Performance of a newly proposed B2C e-commerce model is evaluated based on trust factors and requirements in the context of Saudi Arabia.

(2) The standpoint of the end user is analyzed to determine the influence of the proposed trust requirements and factors on B2C e-commerce in Saudi Arabia.

(3) Adaptable government approaches, enactment, rules, insurance of buyer rights, and banking network situation with less web expenses are demonstrated to be significant to e-commerce expansion in the Kingdom.

The organization of this paper is as follows: Section 2 discusses the proposed model for carrying out this research work. Section 3 provides the various results achieved and discusses the impact of these results based on trust factors and requirements in the context of Saudi Arabia. Conclusion of this paper is provided in Section 4.

\section{Proposed Model}

The standards and structure of different existing models are efficiently examined to build the new B2C model for webbased business in Saudi Arabia. These concepts include the pattern, theoretical formulation, and model development stages, and quantitative or qualitative techniques. Following Henning in [5], the methodology system is considered the sound gathering of methods that adjust one another and are competent to convey exact outcomes. The significant objective of this examination is to decide the effects of trust on B2C electronic business in Saudi Arabia. In particular, the trust factor prerequisites that influence B2C web-based business in Saudi Arabia are recognized, another proficient B2C trust model for web-based business is created dependent on these trust necessities, and the exhibition and legitimacy of the proposed B2C trust model is assessed.

Figure 1 displays the design stages of the present research that is adopted from the earlier research framework [6]. The design consists of five phases: awareness of the problem creation, design, development, assessment to determine the performance accuracy, and outcome of the method. A research proposal is drafted to highlight the existing problems that helped develop the comprehensive B2C e-commerce trust model in Saudi Arabia. These issues are related to the lack of trust in electronic websites, privacy, security, and challenges facing the customer.

The present new B2C trust model is proposed based on trust requirements, including factors such as integration of requirements of trust in Saudi Arabia with the trust factors that lead to increase in the use of the websites of purchase and is shown in Figure 2. These requirements are monitoring and supervision on the websites by the government; making ICT infrastructure; issuance of guidelines and enactment; claiming personal residence and creating a conveyance system; providing dependable, protected, and secure online installment alternatives; shopper assurances; and explaining commercial center standards and affirmation authority. The trust formation factors are real-world presence, user interface, proper branding, perceived benefits from lowering prices of using the Internet, perceived risk from e-crimes, new delivery system (Wasil), technological incentives (security, user privacy, and payment system), and finally, trustworthiness [6].

The evaluation is based on the identified trust requirements and objectives, where a questionnaire is designed by covering these essential identified requirements. The genuineness of the questionnaire is further validated from the customer point of view. The reliability of the proposed model is tested using statistical tools. Data are collected in Saudi Arabia. Sampling is carried out on three age groups of the population in the ranges of 20-34, 35-49, and 50-64 years. A total of 450 samples are distributed for all age groups. Table 1 summarizes the five significant phases of the evaluation.

Table 2 demonstrates a comparison among various trust factors and requirements in $\mathrm{B} 2 \mathrm{C}$ models proposed in the literature. The relationship among them is also outlined.

The main prerequisite of trust in Saudi Arabia is checking and oversight on the websites by the public authority. The public authority should be certain about the brand name alongside its enlistment in the framework and head office. The Saudi government should be answerable for three key capacities, namely, help, management, and control. The Saudi Ministry ICT in 2006 made a public procedure entitled "The National Communications and Information Technology Plan.” The great goal of this arrangement is the change into a data society and computerized economy to upgrade throughput essentially. This goal rendered correspondence and IT offices to each area throughout the nation and fabricated a firm data industry for major monetary turn of events [7].

The second necessity is the formation of an ICT framework for all areas in the general public in the entire Saudi Arabia. As of now, a large portion of the administrations that are delivered by correspondence ventures is 


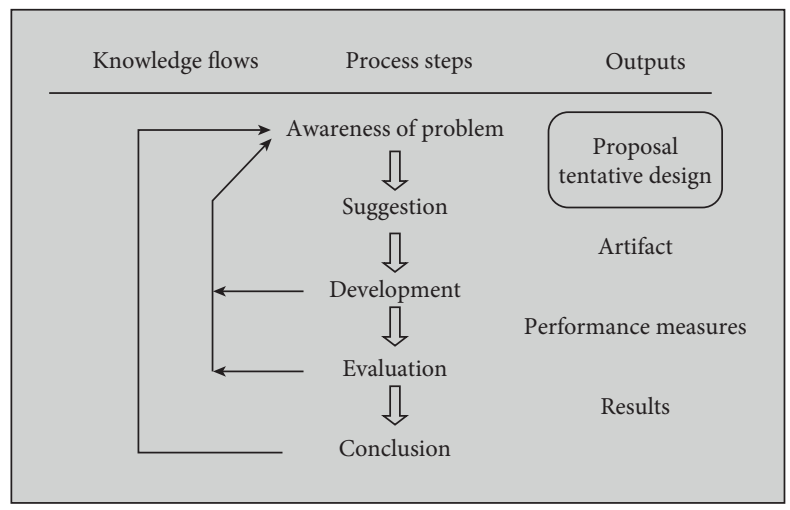

FIGURE 1: Operational framework in [3].

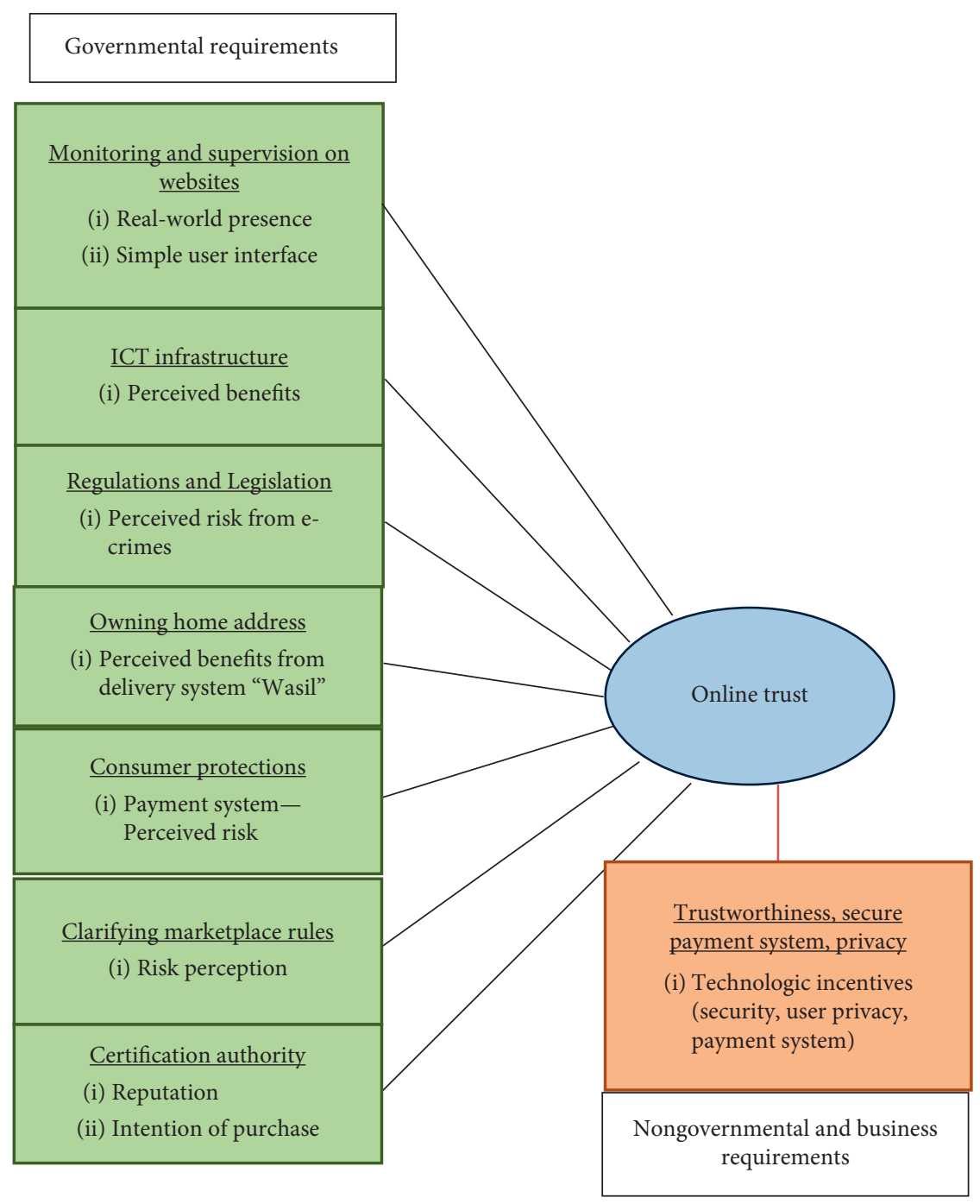

Figure 2: Proposed trust model for B2C e-commerce in Saudi Arabia.

significantly from the main urban areas. A greater part of the small municipalities and towns is denied acceptable web associations or viably with no Internet providers [8]. Indeed, the charges required for web association in Saudi Arabia are higher than the noticeable created nations across the globe.
Correspondence organizations should provide online organizations administrations to towns and far-off regions. Likewise, they ought to survey the association expenses to make it more forthcoming for a larger part of the nationals to energize just as advance the use of web [9]. 
TABLE 1: Various phases of model performance evaluation.

\begin{tabular}{|c|c|c|}
\hline Phases & Main activities & Outputs \\
\hline $\begin{array}{l}\text { Awareness of } \\
\text { problem }\end{array}$ & $\begin{array}{l}\text { Search on limitations of current trust model and the obstacles } \\
\text { facing the customer in B2C e-commerce in Saudi Arabia }\end{array}$ & $\begin{array}{l}\text { Provide research proposal with research objectives } \\
\text { and problem statement }\end{array}$ \\
\hline \multirow{3}{*}{ Suggestions } & $\begin{array}{c}\text { Identify the trust requirements that affect B2C e-commerce in } \\
\text { Saudi Arabia }\end{array}$ & Requirements of trust \\
\hline & Identify the trust formation factors & \\
\hline & $\begin{array}{l}\text { Integration requirements with trust factors to achieve the } \\
\text { research goal }\end{array}$ & Trust formation factors \\
\hline Development & Develop the B2C trust model for Saudi Arabia & Proposed B2C trust model \\
\hline Evaluation & Validation of identified requirements for trust in Saudi Arabia & Verification of the new trust model for e-commerce \\
\hline Conclusion & Conclusion & $\begin{array}{l}\text { Provide the new trust model for B2C electronic } \\
\text { commerce in the context of Saudi Arabia }\end{array}$ \\
\hline
\end{tabular}

TABLE 2: Comparison between the trust requirements and trust models factors based on existing works.

\begin{tabular}{|c|c|c|c|c|c|}
\hline \multirow{7}{*}{ Trust requirements } & \multicolumn{5}{|c|}{ Models } \\
\hline & Belanger (2002) & $\begin{array}{l}\text { Bullington } \\
\text { (2007) }\end{array}$ & $\begin{array}{l}\text { Dan J. Kim } \\
\text { (2008) }\end{array}$ & $\begin{array}{l}\text { Foroozan } \\
\quad(2012)\end{array}$ & Al-Ghamdi (2012) \\
\hline & \multirow{5}{*}{ Trustworthiness } & \multirow{5}{*}{$\begin{array}{c}\text { Risk } \\
\text { perception }\end{array}$} & $\begin{array}{l}\text { Perceived } \\
\text { benefits }\end{array}$ & $\begin{array}{l}\text { Real-world } \\
\text { presence }\end{array}$ & $\begin{array}{l}\text { Consumer } \\
\text { protections }\end{array}$ \\
\hline & & & Dorcoived ricl & & Providing \\
\hline & & & Perceived risk & Savinty & Delivery system \\
\hline & & & \multirow{2}{*}{$\begin{array}{l}\text { Intention of } \\
\text { purchase }\end{array}$} & $\begin{array}{l}\text { Proper } \\
\text { branding }\end{array}$ & $\begin{array}{l}\text { Certification } \\
\text { authority }\end{array}$ \\
\hline & & & & & $\begin{array}{c}\text { Clarifying } \\
\text { marketplace rules }\end{array}$ \\
\hline $\begin{array}{l}\text { Monitoring and supervision on the } \\
\text { websites by the government }\end{array}$ & - & - & - & $\checkmark$ & - \\
\hline Creating ICT infrastructure & - & - & $\checkmark$ & - & - \\
\hline Issuance of regulations and legislation & - & - & $\checkmark$ & - & - \\
\hline $\begin{array}{l}\text { Owning home address and developing } \\
\text { delivery system }\end{array}$ & - & - & - & - & $\checkmark$ \\
\hline Customer securities & - & - & $\checkmark$ & $\checkmark$ & $\checkmark$ \\
\hline Illuminating regulations of marketplace & - & $\checkmark$ & - & - & $\checkmark$ \\
\hline Accreditation body & - & - & $\checkmark$ & $\checkmark$ & $\checkmark$ \\
\hline $\begin{array}{l}\text { Providing trustworthy, private, and secure } \\
\text { online payment options }\end{array}$ & $\checkmark$ & - & - & $\checkmark$ & $\checkmark$ \\
\hline
\end{tabular}

The third prerequisite of trust in Saudi Arabia is the issuance of guidelines and enactment. The legislature of Saudi Arabia assumes a critical job in rebuilding the documentations and guidelines for native e-commerce development [10]. Notwithstanding focusing on rules to determine the battle among different gatherings, clear online business guidelines for the discipline of electronic wrongdoings should be reported. Accordingly, government association should set up web-based shopping rules, guidelines, and enactment to ensure all elaborate gatherings by guaranteeing trust. As of now, the government should play a more dynamic, proactive job notwithstanding the improvement measures [11]. Most of the exploration on Saudi Arabian Internet business uncovers that the insufficiency of government guidelines is indispensable for the acknowledgment and usage of web-based business in the country.

The acquisition of a home address to developing an efficient, effective delivery system is a key component in B2C growth. Conveyance framework is the central factor for webbased business clients' administration to make the administrations ideal with less expensive rates [12]. With respect to obtaining web-based business administrations, Saudi Arabian nationals are experiencing three first difficulties, namely, the inadequacy of a designated house address, not obtaining their ideal possessions and offices, and costly conveyance civilities. These impediments prevent clients from taking advantage of Internet-business-related administrations regardless of their familiarity with a few striking focal points.

Fifth, a body for shopper security controls traditional Internet business in Saudi Arabia. Nonetheless, Saudi nationals are unsatisfied with this body because of their inert part in covering and empowering the web clients in B2C Internet business. Buyers are not trustful of this organizations' insurance framework and are not ready to ask them or gripe for disconnected exchanges. In this way, the importance of having such guidelines for buyer is vital for 
compromises, online business practice, and customer security for exchanges led on the web [13]. The rights and duties of the clients can be exemplified given the standards and guidelines as clear rules are characterized in an online commercial center. The online business is required to develop if the clients are persuaded and surely know these standards. Genuinely, the laws, rules, and guidelines in Saudi Arabia for customary business are not straightforward or clear. Moreover, the law for Internet business in the nation is fairly dark. Although Saudi Arabia significantly adds to the endeavors of the United Nations Commission into International Trade Laws [14], more activities are important to fortify the online business for quick monetary turn of events.

Confirmation expert in the web-based setting is fundamental because site clients are not prepared for online purchase without the setup of trust of a specific organization they are keen on. Items with brand name do not encounter any trouble in obtaining the dependence of the clients. Affirmation authority assists novel, nearly new sites to build trust with new clients or shoppers [14]. At last, furnishing a dependable framework with outright protection and ensuring online installment choices should be needed. This necessity is critical to build the trust level in web-based business in Saudi Arabia. Saudi banks should build customer mindfulness about Visa and its significance to confront the security concerns when shopping on the web. Banks should target youthful Saudis by offering them simple-to-obtain preloaded Visas. Notwithstanding preloaded cards that can be connected to PayPal, banks likewise ought to deal with permitting their clients to associate their PayPal records with their charge accounts. SADAD is a current e-installment framework in Saudi Arabia that was dispatched in 2004 [15-17]. The focal order for SADAD is to facilitate and rearrange exchanges for charge installment of end clients utilizing all financial organizations of the Kingdom. All these requirements are incorporated into the trust model to set up the questionnaire for data collection.

\section{Results and Discussion}

Data are collected via a quantitative approach, where the questionnaire contains the demography, and the requirements are identified. The design of questions includes every requirement and the factors of trust models to confirm their strong correlation with the requirements. Additional notes as an open question are also provided for clarity. The content of the questionnaire is validated by expert lecturers to ensure that it is well organized and easy to understand. These questionnaires are distributed randomly among 222 female and male respondents. Data are collected over a period of 10 weeks.

Table 3 summarizes the structure of the final questionnaire. The first column of the questionnaire shows the e-commerce trust requirements in Saudi Arabia, the second column shows the questions of each requirement based on the trust factors related to that requirement, and the last column represents the ID of each question to make analysis easy and achievable. The aim of part for the questionnaire is to know the end user standpoint regarding the proposed requirements and how these requirements can increase the level of trust in e-commerce.

3.1. Data Analysis. The survey questions involve the end user's opinion toward the importance of the proposed requirements to increase the level of trust in e-commerce. These analyses include the following demographic analysis, requirements, descriptive statistics, and factors.

\subsubsection{Demographic Analysis (Part A of the Questionnaire).} The first part of the questionnaire consists of five closeended questions related to the respondent's background, such as age, gender, education level, experience in using e-commerce website, and the number of times of purchasing online. Tables 4 and 5 list the details of respondents' information in terms of age and gender. Clearly, the majority of the respondent ages, $37.0 \%$, is represented the range between 20 and 34 years old. The ages in the range of 35-49 represent $32.4 \%$, and the last group that is between 50 and 64 years old corresponds to $30.6 \%$.

Most of the respondents are male, 125 people out of 222, which represents $56.3 \%$ of the respondents, while the rest of the respondents are female with approximately $43.7 \%$, as listed in Table 5. Table 6 outlines the educational level of the respondents, where the highest number represents Bachelor's degree holders (44.1\%), 38.3\% are Master degree holders, $14 \%$ are Ph.D. degree holders, and the rest (3.6\%) are Diploma holders.

Table 7 demonstrates that the highest number of respondents (96) are experienced in e-commerce websites between 2 and 4 years (43.2\%), and 47 of them have been using these websites for 5 to 7 years (21.2\%). Approximately $20 \%$ of the respondents have been using these websites for less than 1 year, whereas 19 respondents have acquired a good experience (between 8 and 10 years). A total of 16 respondents have more than 10 years of experience (7.2\%).

Table 8 reveals the respondent information regarding the frequency of buying online. Most respondents buy one to two times per month, which amounts to $30.1 \%$. About $28.8 \%$ of the total responders make online purchases of one to two times per year. About $16.2 \%$ buy more than two times per year, whereas $14.9 \%$ of the respondents purchase online more than two times per month. Approximately $10 \%$ of the respondents never purchased online.

\subsubsection{Requirement Analysis (Part B of the Questionnaire).} This part of the questionnaire considers the issues regarding the requirements and trust factors. The main aim of this part is to determine the extent of these requirements to increasing the trust level while using the e-commerce website in Saudi Arabia. SPSS is used to analyze the collected data. Cronbach's alpha is employed to analyze the reliability of the questionnaire, measure the internal consistency, and ensure their correlation. These items are considered reliable if the value of 0 Cronbach's alpha is greater than 7 . The results are summarized in Tables 9 and 10 [16]. Data in Table 9 clearly show that all the answers are provided in the entire 
TABLE 3: Summary of the structure of the final questionnaire.

Requirements
$\begin{aligned} & \text { (1) The government should be sure whether a website is an extension of a familiar } \\ & \text { offline company, or it is the only touch point with an unknown company. }\end{aligned}$
$\begin{aligned} & \text { Supervision on the e-commerce } \\ & \text { websites by the government }\end{aligned}$
$\begin{aligned} & \text { (2) Website quality and security and privacy statement support trust and intention } \\ & \text { to shop online. }\end{aligned}$
$\begin{aligned} & \text { (3) Proper brand is a vital factor in stimulating purchases over the Internet. } \\ & \text { SEWG3 }\end{aligned}$
(5) Increase the speed of internet connection helps to use e-commerce sites.

(6) Government must set up online shopping rules, regulations, and legislation is important to make consumers feel very comfortable in buying from Internet.

Issuance of regulations and legislation (7) The significance of having regulations for consumer is crucial for conflict

$\begin{array}{cc}\text { (7) The significance of having regulations for consumer is crucial for conflict } & \text { IRL2 } \\ \text { resolutions and online business practice. } & \end{array}$

IRL1

(8) The absence of regulations and legislation facilitates fraud and e-crimes. IRL3

(9) The lack of an efficient postal system is determined to be disadvantageous to OHADDS1 consumers.

Owning home address and develop delivery system
(10) The lack of a home address is a major challenge that faced by consumer.

(11) Not receiving the goods and services on time makes the consumer does not trust in the e-commerce.

(12) "Wasil" delivery system must provide all its services to all regions of the Kingdom.
OHADDS2

OHADDS3

OHADDS4
TABLE 4: Information on respondents' age.

\begin{tabular}{lcc}
\hline Respondents' age & Number of participants & $\%$ \\
\hline $20-34$ years old & 83 & 37.0 \\
$35-49$ years old & 72 & 32.4 \\
$50-64$ years old & 68 & 30.6 \\
Total & 222 & 100 \\
\hline
\end{tabular}

TABLE 5: Information on respondents' gender.

\begin{tabular}{lcc}
\hline Respondents' gender & Number of participants & $\%$ \\
\hline Male & 125 & 56.3 \\
Female & 97 & 43.7 \\
Total & 222 & 100 \\
\hline
\end{tabular}

TABLE 6: Education level of the respondents.

\begin{tabular}{lcc}
\hline Education level & Number of participants & $\%$ \\
\hline Diploma & 8 & 3.6 \\
Bachelor's & 98 & 44.1 \\
Master & 85 & 38.3 \\
Ph.D. & 31 & 14.0 \\
Total & 222 & 100 \\
\hline
\end{tabular}

questionnaire. The value of Cronbach's alpha of $0.947 \mathrm{im}$ plies that all the requirements in the questionnaire demonstrate an acceptable reliability for this research.

3.1.3. Descriptive Statistical Analysis. This part demonstrates the descriptive statistics analysis for the eight trust requirements and its factors. The questionnaire consists of five options, namely, 1: strongly disagree, 2: disagree, 3: neutral, 4: agree, and 5: strongly agree. The descriptive statistics (SEWG1, SEWG2, and SEWG3) for the first requirement
TABLE 7: Respondents' years of experience in using e-commerce websites.

\begin{tabular}{lcc}
\hline $\begin{array}{l}\text { Experience in using e-commerce } \\
\text { website }\end{array}$ & $\begin{array}{l}\text { Number of } \\
\text { participants }\end{array}$ & $\%$ \\
\hline Less than 1 year & 44 & 19.8 \\
2-4 years & 96 & 43.2 \\
5-7 years & 47 & 21.2 \\
8-10 years & 19 & 8.6 \\
More than 10 years & 16 & 7.2 \\
Total & 222 & 100 \\
\hline
\end{tabular}

TABLE 8: Statistics on the frequency of buying online.

\begin{tabular}{lcc}
\hline Frequency of buying online & Number of participants & $\%$ \\
\hline Never & 22 & 10 \\
1-2 times per month & 67 & 30.1 \\
More than 2 times per month & 33 & 14.9 \\
1-2 times per year & 64 & 28.8 \\
More than 2 times per year & 36 & 16.2 \\
Total & 222 & 100 \\
\hline
\end{tabular}

(supervision on the e-commerce websites by the government) listed in Table 11 reveals large mean values and standard deviation. Therefore, the factors related to this requirement are significant from the view point of the responders.

Table 12 lists the results of descriptive statistics for the second requirement (creating ICT infrastructure). It contains one factor only and two questions (CICT1 and CICT2). These factors display a higher mean from the responders' standpoint.

Descriptive statistics for the requirement of issuance of regulations and legislation is presented in Table 13. Three questions (IRL1, IRL2, and IRL3) are provided to measure the effect of perceived risk from e-crimes on this 
TABLE 9: Case processing summary.

\begin{tabular}{cccc}
\hline & & $N$ & $\%$ \\
\hline \multirow{3}{*}{ Cases } & Valid & 222 & 100 \\
& Excluded & 0 & 0 \\
& Total & 222 & 100 \\
\hline
\end{tabular}

TABLE 10: Reliability statistics for questionnaire.

Cronbach's alpha

Number of items

0.947 27

TABLE 11: Descriptive statistics of the government's supervision of e-commerce websites.

\begin{tabular}{lccc}
\hline & $N$ & Mean & Std. deviation \\
\hline SEWG1 & 222 & 4.5495 & 0.57455 \\
SEWG2 & 222 & 4.5676 & 0.49653 \\
SEWG3 & 222 & 4.5631 & 0.49713 \\
Valid N (list-wise) & 222 & - & - \\
\hline
\end{tabular}

TABle 12: Descriptive statistics of creating ICT infrastructure.

\begin{tabular}{lccc}
\hline & $N$ & Mean & Std. deviation \\
\hline CICT1 & 222 & 4.5856 & 0.49373 \\
CICT2 & 222 & 4.5721 & 0.49590 \\
Valid N (list-wise) & 222 & - & - \\
\hline
\end{tabular}

TABle 13: Descriptive statistics of issuance of regulations and legislation.

\begin{tabular}{lccc}
\hline & $N$ & Mean & Std. deviation \\
\hline IRL1 & 222 & 4.5631 & 0.49713 \\
IRL2 & 222 & 4.5991 & 0.49119 \\
IRL3 & 222 & 4.6036 & 0.49025 \\
Valid N (list-wise) & 222 & - & - \\
\hline
\end{tabular}

requirement. The results clearly indicate that the issuance of regulations and legislation in Saudi Arabia is very important to reduce the perceived risk of e-crimes.

Descriptive statistics for the requirement of owning a home address and a proper delivery system is summarized in Table 14. The obtained value of the highest mean signifies that the participants agree with the factor perceived benefits from delivery system "Wasil," which is strongly correlated to the requirement of owning a home address and developing a delivery system.

Table 15 lists the descriptive statistics of consumer protections. The achievement of higher means for all the questions signifies that the Consumer Protection Agency in
Saudi Arabia must provide secure payment options to reduce the potential risks to users of e-commerce websites.

In Table 16, the occurrence of higher means for most of the items indicates that all of them are essential and significant from the end user point of view. The rules of the market must be clarified through the provision of perceptions of the potential risks of dealing with e-commerce websites. Assessing the reputation of e-commerce websites allows users to use the website for purchase or otherwise, and this makes the registration of website certification essential in the Chamber of Commerce.

Table 17 outlines the descriptive statistics for the last requirement (providing trustworthy, private, and secure online payment options). This requirement with their factor consists of five questions (PTPS1, PTPS2, PTPS3, PTPS4, and PTPS5). The factor of this requirement has a higher mean and standard deviation. Therefore, the provision of technological incentives is necessary to make the user feel privacy and trustworthiness.

The above analyses in terms of descriptive statistics clearly demonstrate that the proposed trust model produces an excellent performance because the majority of participants agree that the factors are closely related to the identified requirements. Moreover, all the components of the model are important for increasing the level of trust in e-commerce websites in Saudi Arabia.

3.1.4. Significance Level. The results in Table 18 clearly show that the skewness value is in between -2.58 and +2.58 . Furthermore, the appearance of the significance level at 0.01 clearly indicates that all the requirements are significant to raise the trust in using e-commerce website in Saudi Arabia $[18,19]$. The results further assert that the proposed trust model does not require any change because the majority of participants agree that the factors are closely related to the identified requirements. In addition, all the components of the model achieve high values in the significance level.

Based on the statistical analysis carried out, our work provides an insight that there is a significant relationship existing between the trust constructs and information quality services, quality user interface, and orientation of markets in Saudi Arabia. Our study provided the contribution in terms of novel B2C model that will help in improving processes required for understanding of design of e-commerce websites and improve the features that will help in gaining market orientation information service quality. Moreover, the analyses in terms of descriptive statistics reveal that the proposed trust model produces an excellent performance for the factors that are closely related to the identified requirements in comparison to the work given in [14]. All the components of the model are found responsible for enhancing the level of trust in e-commerce websites in Saudi Arabia with a significance level of 0.01 . 
TABLE 14: Descriptive statistics of owning home address and proper delivery system.

\begin{tabular}{lccc}
\hline & $N$ & Mean & Std. deviation \\
\hline OHADDS1 & 222 & 4.5856 & 0.49373 \\
OHADDS2 & 222 & 4.5991 & 0.49119 \\
OHADDS3 & 222 & 4.5901 & 0.49293 \\
OHADDS4 & 222 & 4.5405 & 0.49948 \\
Valid N (list-wise) & 222 & - & - \\
\hline
\end{tabular}

TABle 15: Descriptive statistics of consumer protection.

\begin{tabular}{lccc}
\hline & $N$ & Mean & Std. deviation \\
\hline CP1 & 222 & 4.5586 & 0.49768 \\
CP2 & 222 & 4.5135 & 0.50095 \\
CP3 & 222 & 4.5405 & 0.49948 \\
CP4 & 222 & 4.5676 & 0.49653 \\
Valid N (list-wise) & 222 & - & - \\
\hline
\end{tabular}

TABle 16: Descriptive statistics for clarifying marketplace rules and certification authority.

\begin{tabular}{lccc}
\hline & $N$ & Mean & Std. deviation \\
\hline CMR1 & 222 & 4.5856 & 0.49373 \\
CMR2 & 222 & 4.5360 & 0.49983 \\
CA1 & 222 & 4.5180 & 0.50080 \\
CA2 & 222 & 4.5586 & 0.49768 \\
CA3 & 222 & 4.5631 & 0.49713 \\
CA4 & 222 & 4.5405 & 0.49948 \\
Valid N (list-wise) & 222 & - & - \\
\hline
\end{tabular}

TABLE 17: Descriptive statistics of providing trustworthy, private, and secure online payment options.

\begin{tabular}{lccc}
\hline & $N$ & Mean & Std. deviation \\
\hline PTPS1 & 222 & 4.5766 & 0.49522 \\
PTPS2 & 222 & 4.5901 & 0.49293 \\
PTPS3 & 222 & 4.5586 & 0.49768 \\
PTPS4 & 222 & 4.5811 & 0.49450 \\
PTPS5 & 222 & 4.5495 & 0.49866 \\
Valid N (list-wise) & 222 & - & - \\
\hline
\end{tabular}

TABLE 18: Significance level for the trust requirements.

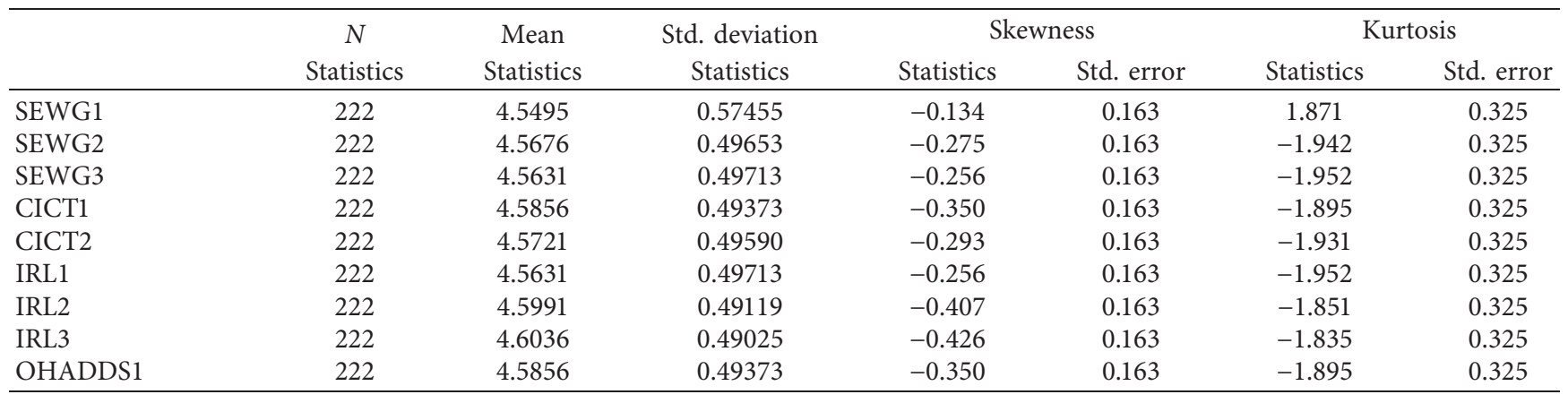


TABle 18: Continued.

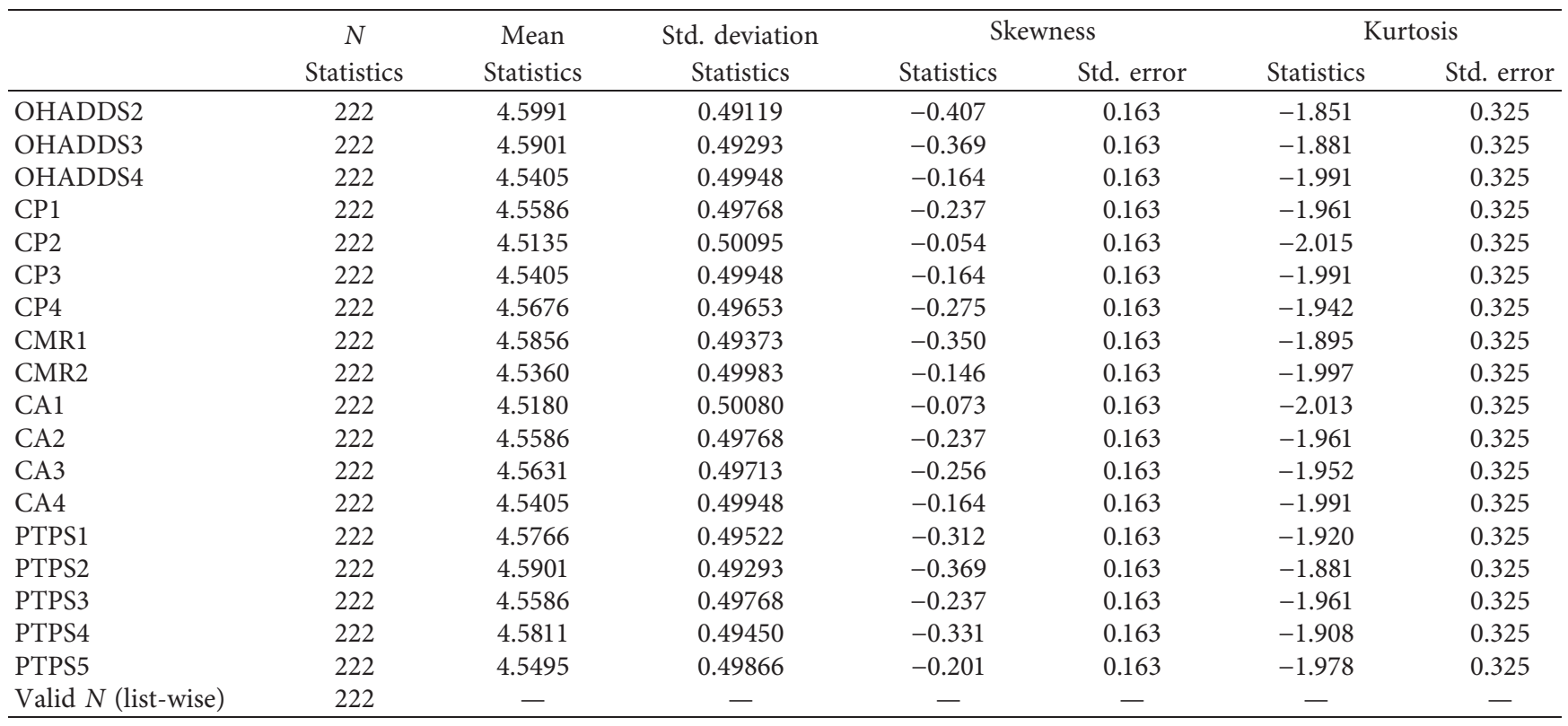

\section{Conclusion}

The performance of a newly proposed $\mathrm{B} 2 \mathrm{C} \mathrm{e}$-commerce trust model that provides security and reliance of e-commerce growth in Saudi Arabia is evaluated. This trust model is developed based on consumers' expectation for online shopping. A valid questionnaire is designed based on the identified essential requirements or major influencing factors of reliance. These questionnaires are then randomly distributed among 222 academic and administrative staff as well as university students in Saudi Arabia. The collected data from all respondents are statistically analyzed using SPSS, where the values of mean, standard deviations, and skewness are calculated to determine the possible influence of these trust requirements and factors on $\mathrm{B} 2 \mathrm{C} \mathrm{e}$-commerce. The importance of these requirements to promoting the trust among e-commerce website users in Saudi Arabia is demonstrated. The analyses in terms of descriptive statistics reveal that the proposed trust model produces an excellent performance because the majority of participants agree that the factors are closely related to the identified requirements. All the components of the model are found responsible for enhancing the level of trust in e-commerce websites in Saudi Arabia with a significance level of 0.01 . The results verify (large mean and skewness values) that the proposed trust model contains all the essential ingredients of trust and privacy for e-commerce advancement in Saudi Arabia. Higher values in the significance level and means are achieved for all the requirements. The results establish that flexible government policies, legislation, rules, protection of consumer rights, and banking network system with less Internet fees can augment the $\mathrm{B} 2 \mathrm{C}$ e-commerce in the Kingdom. This new model may constitute a basis to exploring the feasibility of strong e-commerce growth in developing nations.

\section{Limitations of the Present Study and Future Directions}

The data was collected for this study from the randomly distributed among 222 academic and administrative staff (female and male) in addition to university students from the Faculty of Computer Science and Information System in Saudi Arabia. For future research, it is recommended to gather data from individuals belonging to other regional universities as well to identify more accurately the impact of trust factors on $\mathrm{B} 2 \mathrm{C}$ model for e-commerce applications. The current study needs to be extended in evaluating B2C model for other factors of service quality, customer service, and security and privacy.

\section{Data Availability}

The data used to support the findings of this study are available from the corresponding author upon request.

\section{Conflicts of Interest}

The authors declare that they have no conflicts of interest regarding the publication of this paper.

\section{Authors' Contributions}

The authors of this research article have contributed equally.

\section{Acknowledgments}

This work was supported by Taif University Researchers' Supporting Project no. TURSP-2020/215, Taif University, Taif, Saudi Arabia. 


\section{References}

[1] S. Shreya and K. Chatterjee, "A dynamic trust model based on user interaction for E-commerce," in Recent Findings in Intelligent Computing Techniques, pp. 433-443, Springer, Singapore, 2019.

[2] Y. Choi and D. Q. Mai, "The sustainable role of the e-trust in the B2C e-commerce of Vietnam," Sustainability, vol. 10, no. 1, p. 291, 2018.

[3] P. Fingar, "Component-based frameworks for e-commerce," Communications of the ACM, vol. 43, no. 10, pp. 61-67, 2000.

[4] S. R. Saleh, E. M. Khaneghah, N. Shadnosh, and A. R. Showkatabad, "A mathematical model to adopt B2C ecommerce based on special customer requirement in social values with an emphasis on Islamic beliefs," Journal of Islamic Marketing, vol. 10, no. 4, pp. 1167-1195, 2019.

[5] K. J. Henning, "What is research methodology?" Morbidity and Mortality Weekly Report, vol. 53, pp. 7-11, 2004.

[6] V. Vaishnavi and W. Kuechler, Design Science Research Methods and Patterns Innovating Information and Communication Technology, CRC Press, Boca Raton, FL, USA, 2015.

[7] MCIT "(Saudi Ministry of Communication and Information Technology)". In 2006 from ICT http://www.mcit.gov.sa/ english/Development/SectorIndices/.

[8] F. Aleid, S. Rogerson, and B. Fairweather, "A consumers" perspective on E-commerce: practical solutions to encourage consumers' adoption of E-commerce in developing countriesa Saudi Arabian empirical study," in Proceedings of the 2010 IEEE International Conference on Advanced Management Science, vol. 2, pp. 373-377, Chengdu, China, July 2010.

[9] S. Alfuraih, "E-Commerce and E-commerce fraud in Saudi Arabia: a case study," in Proceedings of the 2nd International Conference on Information Security and Assurance, pp. 176-180, IEEE, Busan, Korea, April 2008.

[10] H. R. Cheeseman, Business Law: Ethical, International \& E-Commerce Environment, Prentice Hall, Hoboken, NJ, USA, 2001.

[11] P. P. Polanski and R. B. Johnston, "International custom as a source of law in global electronic commerce in system sciences," in Proceedings of the 35th Annual Hawaii International Conference on System Sciences, Big Island, HI, USA, January 2002.

[12] F. Al-Sobhi, V. Weerakkody, and M. M. Kamal, "An exploratory study on the role of intermediaries in delivering public services in madinah city: case of Saudi Arabia," Transforming Government: People, Process and Policy, vol. 4, no. 1, pp. 14-36, 2010.

[13] E. Makki and L. C. Chang, "E-commerce in Saudi Arabia: acceptance and implementation difficulties," in Proceedings of the International Conference on e-Learning, e-Business, Enterprise Information Systems, and e-Government (EEE), Las Vegas, NV, USA, July 2014.

[14] R. AlGhamdi, A. T. A. Nguyen, and V. Jones, "Wheel of B2C E-commerce development in Saudi Arabia," in Robot Intelligence Technology and Applications 2013, pp. 1047-1055, Springer, Berlin, Germany, 2013.

[15] SADAD, "SADAD Payment System," viewed Oct 2010, http:// www.sadad.com/English/SADAD+SERVICES/AboutSADAD.

[16] J. M. Bland and D. G. Altman, "Statistics notes: cronbach's alpha," BMJ, vol. 314, no. 7080, p. 572, 1997.

[17] J. F. Hair, C. M. Ringle, and M. Sarstedt, "Editorial-partial least squares structural equation modeling: rigorous applications, better results and higher acceptance," Long Range Planning, vol. 46, no. 1-2, pp. 1-12, 2013.
[18] S. Ali, N. Ullah, M. F. Abrar, Z. Yang, and J. Huang, "Fuzzy multicriteria decision-making approach for measuring the possibility of cloud adoption for software testing," Scientific Programming, vol. 202024 pages, 2020, p, Article ID 6597316.

[19] S. Ali, J. Huang, S. U. Khan, and H. Li, "A framework for modelling structural association amongst barriers to software outsourcing partnership formation: an interpretive structural modelling approach," Journal of Software: Evolution and Process, vol. 32, no. 6, p. e2243, 2020. 